\title{
First Report of Multi-resistant Escherichia fergusonii Isolated from Children Under Two Months of Age in Intensive Care Unit
}

\author{
Mildred Azucena Rivera-Galindo ${ }^{1}$, Gauddy Lizeth Manzanares-Leal ${ }^{1}$, Luz Marcela Caro-Gonzalez ${ }^{2}$, \\ Erika Santos-Ramirez ${ }^{2}$, Hugo Mendieta-Zeron ${ }^{2,3}$, Horacio Sandoval-Trujillo $^{4}$ and Ninfa \\ Ramirez-Duran ${ }^{1, *}$ \\ ${ }^{1}$ Laboratory of Medical and Environmental Microbiology, Faculty of Medicine, Autonomous University of the State of Mexico, Mexico City, México \\ 2 "Monica Pretelini Saenz" Maternal-Perinatal Hospital, Ministry of health, Toluca, México \\ ${ }^{3}$ Faculty of Medicine, Autonomous University of the State of Mexico, Toluca, Mexico \\ ${ }^{4}$ Department of Biological Systems, Autonomous Metropolitan University-Xochimilco, Mexico City, México \\ "Corresponding author: Laboratory of Medical and Environmental Microbiology, Faculty of Medicine, Autonomous University of the State of Mexico, Toluca, 50180 Mexico, \\ Mexico.Email: ninfard@hotmail.com
}

Received 2021 May 08; Revised 2021 July 04; Accepted 2021 July 06.

\begin{abstract}
Background: Gram-negative bacilli are primarily responsible for the most common pediatric infections. Frequently, Escherichia fergusonii is identified as E. coli because of its close genetic proximity.

Objectives: We aimed at the isolation and identification of multi-resistant strains of E. fergusonii, affecting children under two months of age.

Methods: Strains were isolated from infectious processes and were identified phenotypically and molecularly. The microdilution method (MicroScan, autoSCAN-4) and the disk diffusion method (modified Kirby Bauer) were used to analyze antibiotic susceptibility.

Results: Strains isolated were multi-resistant. Molecular identification provided the correct taxonomic assignment. Escherichia fergusonii strains were wrongly identified as E. coli with the phenotypic identification method. In addition, Pseudomonas aeruginosa and Klebsiella pneumoniae were identified. The best sensitivity results were obtained with Ceftazidime/avibactam and ceftolozane/tazobactam.

Conclusions: We provided the first report of isolation and identification of multi-resistant E. fergusonii strains affecting children under two months of age in a neonatal intensive care unit.
\end{abstract}

Keywords: Multi-resistant Bacteria, Antibiotics, Phenotypic Identification, Molecular Identification, Escherichia fergusonii

\section{Background}

Antibiotic resistance is expected to cause more deaths than cancer by 2050 , and it poses a severe threat to public health $(1,2)$. Multidrug-resistant gram-negative bacilli are the most frequent causes of sepsis and pneumonia in newborns, causing death $(3,4)$. Escherichia coli is one of the most common ones (5-7). There are eight recognized species in the genus Escherichia (8). Escherichia coli is the most studied one (9). Its closest relative is E. fergusonii, with $64 \%$ genetic similarity $(10,11)$. The proximity between the two species gives rise to identification problems, depending on the method used.

With the use of phenotypic methods, E. fergusonii is usually identified as E. coli $(12,13)$. Epidemiologically, bacterial misclassification leads to underreporting pathogenic microorganisms. Escherichia fergusonii emerges as a microorganism of concern because of its potential for multidrug resistance; however, it is underreported (13-15). There are three reports of isolation in humans; two are clinical cases $(14,15)$, and only one reports strains found in different patients (13). Currently, the prevalence and incidence of cases in which the bacterium causes disease are not known precisely. It is also not known exactly how often it becomes resistant to antimicrobial therapy. 


\section{Objectives}

We aimed to present the first report on the isolation and molecular identification of multidrug-resistant $E$. fergusonii strains (previously identified as E. coli) in infants less than two months old in a neonatal intensive care unit.

\section{Methods}

\subsection{Samples}

A descriptive cross-sectional study was performed. Samples of peripheral blood $(n=3)$, central blood $(n=1)$, pleural fluid $(\mathrm{n}=1)$, urine $(\mathrm{n}=2)$, and injury discharge $(n=2)$ were collected from patients under two months of age, admitted to the Neonatal Intensive Care Unit of the Maternal-Perinatal Hospital "Mónica Pretelini Sáenz" of the Instituto de Salud del Estado de México (ISEM) in Toluca, Mexico, from October 2019 to February 2020. Epidemiological data were collected from each patient.

\subsection{Culture}

All samples were inoculated on the culture media, blood agar (Condalab 1108), Mannitol Salt (BD-BBL 254027), McConkey (BD-BBL 211662), and Biggy Agar (BDBBL 255002). The specific treatment of each sample was as follows. Blood samples were placed in BacT/ALERT culture medium (Biomerieux 10853) to optimize bacterial recovery. They were subsequently inoculated by a cross streak in the media already described. Pleural fluid and urine samples were centrifuged at $2500 \mathrm{rpm}$ for $10 \mathrm{~min}$, and the sediments obtained were inoculated by cross streak. Injury discharge samples were collected using the "Culture Swab Collection \& Transport System" (BBL HFT016) and inoculated by cross streak swabbing. All inoculated culture media were incubated at $35 \pm 2{ }^{\circ} \mathrm{C}$ for $24 \mathrm{~h}$. The macroscopic and microscopic morphological characteristics of each strain were described.

\subsection{Phenotypic Identification and Antimicrobial Susceptibility Test with Microdilution Broth Method}

Phenotypic identification and antibiotic susceptibility testing with the microdilution method were performed with the MicroScan (autoSCAN-4, Beckman Coulter®) according to the manufacturer's instructions. Neg Combo 67 (Beckman Coulter B1017-421) was used, which included the following antibiotic families: Aminoglycosides, Beta-lactams, Glycyclines, Polymyxins, Quinolones, Sulfonamides, and Tetracyclines.
3.4. Complementary Antibiotic Resistance Test by the Modified Kirby-Bauer Disk Diffusion Method

The strains were subsequently tested for resistance by disk diffusion using the modified Kirby-Bauer method, with the addition of antibiotics not examined in the microdilution test. In addition, antibiotics from the Phenicol, Phosphonate, and Nitrofuran families were added. A pure 18 - 24 h culture equivalent to $0.5\left(1.5 \times 10^{8}\right.$ cells $)$ on the McFarland scale was used. Discs with the selected antibiotics were placed in a Müller Hinton agar plate (BIO-RAD 63824 ) and incubated under aerobic conditions at $35 \pm 2{ }^{\circ} \mathrm{C}$ for 18 - $24 \mathrm{~h}$. For reading, the edge of the halo was visible to the naked eye at the point of complete inhibition from the back of the Petri dish against a black background illuminated with reflected light (16). The diameter was measured in millimeters and interpreted according to the CLSI M100 guide as sensitive (S), intermediate (I), or resistant (R) (16). Multi-resistance was defined as simultaneous resistance to three or more families of antibiotics from a minimum of 10 families (17). The collection strain E. coli ATCC® 25922 was used for quality control (16).

\subsection{Molecular Identification}

Each strain was seeded in an enriched medium (BHI), and incubated at $35 \pm 2{ }^{\circ} \mathrm{C}$ for 18 - $24 \mathrm{~h}$ under aerobic conditions. Biomass was collected, centrifuged at 9,000 rpm for five minutes, and the supernatant was decanted. The Wizard® Genomic DNA Purification Kit (Promega A1120) protocol was used to extract the genomic DNA, and the quality was checked by electrophoresis on a $1 \%$ agarose gel under the following conditions: $120 \mathrm{~V}$ for 30 minutes with TAE buffer 1X (TAE buffer Invitrogen 5M0311). The concentration was quantified in the EPOCH spectrophotometer (BioTek) at 260 and $280 \mathrm{~nm}$.

Strains were identified by 16S rRNA gene sequencing analysis. Universal primers 27F (5'-AGA GTT TGA TCM TGG CTC AG-3') and 1492R (5'-TAC GGY TAC CTT GTT ACG ACT T-3') were used. The Polymerase Chain Reaction (PCR) was carried out in an Axygen thermal cycler (MaxyGen-II model), using Taq DNA polymerase (Bioline 21105). The conditions were as follows: an initial denaturation cycle of five minutes $\left(94^{\circ} \mathrm{C}\right)$, denaturation of one minute $\left(94^{\circ} \mathrm{C}\right)$, annealing for 30 seconds $\left(59^{\circ} \mathrm{C}\right)$, an extension for one minute $\left(72^{\circ} \mathrm{C}\right)$. Besides, 30 cycles were repeated, followed by a final extension cycle for 10 minutes $\left(72^{\circ} \mathrm{C}\right)$.

The amplification products were observed in $1 \%$ agarose gel electrophoresis under the same conditions used previously, and the concentration was quantified 
with the EPOCH spectrophotometer. The PCR products were purified using the Wizard $®$ SV Gel and PCR Clean-Up System kit (Promega A9282), and then sent to Macrogen $®$ Sequencing Service (Maryland, USA). Sequences were corrected and assembled using BioEdit v7.2.5 software. They were then compared with BLAST (Basic Local Alignment Search Tool) software and the EzBioCloud public database.

\section{Results}

The characteristics of the patients and samples are summarized in Table 1. Nine strains showed multi-drug resistance in the microdilution method and disk diffusion antibiograms. Eight of the nine strains were extendedspectrum beta-lactamase (ESBL) producers (Table 2). The two methods showed that all isolates (100\%) were resistant to aminoglycosides. Within the beta-lactams, nine strains (100\%) were resistant to penicillin and cephalosporins; 77\% were resistant to penicillin with inhibitor; strains Uro6 and Uro42 were the only ones resistant to carbapenems (22\%). Besides, $100 \%$ were resistant to quinolones and sulfonamides, and $88 \%$ were resistant to tetracyclines.

With the microdilution method, sensitivity to tigecycline and colistin was detected in all strains (100\%). Ceftazidime/avibactam and ceftolozane/tazobactam combinations showed the best sensitivity results for all strains tested with the disk diffusion method (Table 2). Bacterial identification by phenotypic and molecular methods showed differences in the taxonomic assignment of $E$. fergusonii. Using molecular identification, strains Uro6, Sec23, and Sec15, phenotypically categorized as E. coli, were identified as E. fergusonii. In addition, five strains were identified as Klebsiella pneumoniae and one as Pseudomonas aeruginosa. These results were consistent with both identification methods. Complete identification data are shown in Table 3.

\section{Discussion}

Neonatal sepsis is one of the leading causes of mortality in Mexico (3-7). The detection of multidrug-resistant bacteria is essential for infection control, preventing their spread and unfavorable morbidity and mortality implications. The appropriate use of antimicrobials represents positive variables to reduce the burden of neonatal sepsis (18). In this study, E. fergusonii was identified by phenotypic methods as E. coli. However, by molecular techniques, a more precise identification was achieved, coinciding with previous publications that clarified the need to correctly identify this species to complete a taxonomic assignment and accurate epidemiological report (10-13).

Escherichia fergusonii was mainly isolated from injury discharge, except for strain Uro6, which, together with strain Uro42 ( $P$. aeruginosa), was isolated from urine samples and had the highest antibiotic resistance. Both were the only ones resistant to carbapenems. A previous study revealed a similar pattern in septic wound isolates (13). Our results provide new information about the presence of multidrug-resistant E. fergusonii in urine samples.

In 1993, Funke et al. (19) isolated E. fergusonii from human clinical samples and concluded that the bacterium had pathogenic potential; before this, it had not been associated with clinical infections. Current studies on this subject are limited (19-22), and publications on its multiresistance associated with human pathologies are scarce (13-15). We can affirm that this is the first report of the presence of the bacterium with multidrug-resistant patterns in clinical samples from infants under two months of age admitted to a neonatal intensive care unit.

Strain Uro42, genetically identified as P. aeruginosa, showed resistance to the most significant number of antibiotics tested, including carbapenems. Several studies have addressed the causes of this resistance (23-25). Our results agree with that reported by Mohsen et al. (26), who found $45 \%$ carbapenem-resistant Pseudomonas infection in infected neonates. Carbapenems are the last line of defense against many drug-resistant bacterial infections. Unfortunately, our study reaffirms that conditions due to pathogens resistant to this drug are present in this age group. Klebsiella pneumoniae was the most abundant species, isolated from blood and pleural fluid. It is reported as one of the predominant organisms in this type of patient (26-29). The strains were sensitive to carbapenems in contrast to P. aeruginosa and E. fergusonii. Despite being one of the most frequent bacteria in neonatal sepsis, our results showed that its resistance patterns are lower than those found in the other two species reported.

Although the microdilution technique (MicroScan) is most widely used, the disk diffusion methodology (modified Kirby-Bauer) showed important information, such as enzymatic activity (beta-lactamases, metallo-betalactamases), resistant mutants, antagonism, and synergism between antibiotics; this provides a broader view in the proper interpretation of the antibiogram. The microdilution method (MicroScan) made it possible to determine that the multidrug-resistant strains were sensitive 


\begin{tabular}{|c|c|c|c|c|c|}
\hline Patients & Sex & Age & Diagnosis & Sample Type & Sample Code \\
\hline $\mathbf{1}$ & Male & 60 days & Sepsis & Peripheral blood & Hemo72 \\
\hline 2 & Male & 5 days & Sepsis & Peripheral blood & H1026 \\
\hline 3 & Female & 21 days & Sepsis & Peripheral blood & H1064 \\
\hline 4 & Male & 30 days & Sepsis & Central blood & H1206 \\
\hline 5 & Male & 8 days & Chylothorax & Pleural fluid & Sec2 \\
\hline 6 & Female & 21 days & Sepsis & Urine & Uro6 \\
\hline 7 & Male & 38 days & Transgestational urinary infection & Urine & Uro42 \\
\hline 8 & Male & 14 days & Injury with abscess & Injury discharge & $\operatorname{Sec} 23$ \\
\hline 9 & Male & 14 days & Neural tube deficiency & Injury discharge & Sec15 \\
\hline
\end{tabular}

to tigecycline and colistin. However, these antibiotics are not recommended for children under eight years of age, and colistin is only recommended for children over two years of age $(30,31)$. With the disk diffusion method, it was possible to determine another sensitivity pattern. Ceftazidime/avibactam and ceftolozane/tazobactam may be more useful in practice, specifically for the age group included in this study.

Respecting the study's limitations, we can mention that it included a small number of cases in a single health care hospital. It is difficult to generalize the results because the pathogens found in neonatal sepsis vary worldwide. The type of sepsis was also not determined; this would have provided important information as some studies showed that late sepsis and early-onset sepsis differ in antibiotic susceptibility patterns, but some studies contradict this claim (29). Among the strengths of our study, we can mention that the latest generation antibiotics were used. Besides, two methods were applied to determine resistance patterns, which allowed us to calculate treatment options according to the age of the patients. Phenotypic and molecular methods were tested for correct bacterial identification, which allowed us to determine the presence of E. fergusonii, rarely reported and with an alarming degree of antimicrobial resistance, in a sensitive age group.

\subsection{Conclusions}

Phenotypic testing did not allow reliable identification to species level. The $16 \mathrm{~S}$ rRNA gene sequencing was more accurate for taxonomic assignment. Multidrug-resistant $E$. fergusonii strains were identified for the first time in children younger than two months. Ceftazidime/avibactam and ceftolozane/tazobactam provided the best treatment option for all strains, considering the age characteristics of the patients. The knowledge generated may promote targeted antibacterial therapy. This study may be of great importance to measure the impact on the local epidemiology of E. fergusonii and antimicrobial and multi-drug resistance.

\section{Acknowledgments}

We would like to acknowledgment the master's program in Health Sciences of the Universidad Autónoma del Estado de México, as well as the Consejo Nacional de Ciencia y Tecnología de México (CONACYT) for this work, which is derived from a Master's thesis carried out within the National Postgraduate Quality Program (PNPC-CONACYT). The authors thank the Clinical Laboratory of the MaternalPerinatal Hospital "Mónica Pretelini Sáenz" for collecting strains.

\section{Footnotes}

Authors' Contribution: Study concept and design: MZ ST, and RD; Acquisition of data: CG, SR, and MZ; Analysis and interpretation of data: RG, ML, ST, and RD; Drafting of the manuscript: RG; Critical revision of the manuscript for important intellectual content: ML, ST, and RD; Statistical analysis: RG and ML; Administrative, technical, and material support: MZ and RD; Study supervision: ST and RD.

Conflict of Interests: The authors declared no conflict of interest.

Ethical Approval: The study was approved by the ethics and research committee of the Maternal-Perinatal Hospital "Monica Pretelini Saenz" of Mexico with registration number 2019-08650. 


\begin{tabular}{|c|c|c|c|c|c|c|c|c|c|c|}
\hline \multirow{2}{*}{ Antibiotic Family } & \multirow{2}{*}{ Method } & \multicolumn{9}{|c|}{ Strains } \\
\hline & & Hemo72 & H1026 & H1064 & H1206 & Sec2 & Uro6 & Sec23 & Sec15 & Uro42 \\
\hline \multicolumn{11}{|l|}{ Aminoglycosides } \\
\hline Amikacine & $A^{a}$ & $s$ & $\mathrm{~s}$ & $s$ & I & $\mathrm{s}$ & $\mathrm{s}$ & $s$ & $\mathrm{~s}$ & $\mathrm{R}$ \\
\hline Gentamycin & A & $\mathrm{R}$ & s & $\mathrm{R}$ & $\mathrm{R}$ & $\mathrm{R}$ & s & $s$ & s & $\mathrm{R}$ \\
\hline Netilmicin & $\mathrm{B}^{\mathrm{b}}$ & $\mathrm{R}$ & $\mathrm{R}$ & $\mathrm{R}$ & $\mathrm{R}$ & $\mathrm{R}$ & $\mathrm{R}$ & $\mathrm{R}$ & $\mathrm{R}$ & $\mathrm{R}$ \\
\hline Tobramycin & A & $\mathrm{R}$ & $\mathrm{s}$ & $\mathrm{R}$ & $\mathrm{R}$ & $\mathrm{R}$ & $\mathrm{R}$ & $\mathrm{s}$ & s & $\mathrm{R}$ \\
\hline \multicolumn{11}{|l|}{ Beta-lactam } \\
\hline \multicolumn{11}{|l|}{ Penicillin } \\
\hline Ampicillin & $\mathrm{A}, \mathrm{B}$ & $\mathrm{R}$ & $\mathrm{R}$ & $\mathrm{R}$ & $\mathrm{R}$ & $\mathrm{R}$ & $\mathrm{R}$ & $\mathrm{R}$ & $\mathrm{R}$ & ND \\
\hline Piperazine & A & $\mathrm{R}$ & $\mathrm{R}$ & ND & $\mathrm{R}$ & ND & ND & ND & ND & $\mathrm{R}$ \\
\hline \multicolumn{11}{|l|}{ Penicillin/inhibitor } \\
\hline Amoxicillin/clavulanic acid & A & ND & ND & I & ND & I & $\mathrm{R}$ & s & s & ND \\
\hline Ampicillin/sulbactam & $\mathrm{A}, \mathrm{B}$ & $\mathrm{R}$ & $\mathrm{R}$ & $\mathrm{R}$ & $\mathrm{R}$ & $\mathrm{R}$ & $\mathrm{R}$ & s & s & $\mathrm{R}$ \\
\hline Piperacillin/tazobactam & $\mathrm{A}, \mathrm{B}$ & $\mathrm{R}$ & s & I & I & s & $\mathrm{R}$ & s & s & $\mathrm{R}$ \\
\hline \multicolumn{11}{|l|}{ Carbapenems } \\
\hline Doripenem & B & s & s & s & s & s & $\mathrm{R}$ & s & s & I \\
\hline Ertapenem & A & s & s & s & s & s & $\mathrm{R}$ & s & s & ND \\
\hline Imipenem & A & s & s & $\mathrm{s}$ & $\mathrm{s}$ & s & $\mathrm{R}$ & s & s & $\mathrm{R}$ \\
\hline Meropenem & A & $\mathrm{s}$ & $\mathrm{s}$ & $s$ & s & $\mathrm{s}$ & $\mathrm{R}$ & s & s & $\mathrm{R}$ \\
\hline \multicolumn{11}{|l|}{ First-generation cephalosporin } \\
\hline Cefazolin & в & $\mathrm{R}$ & $\mathrm{R}$ & $\mathrm{R}$ & $\mathrm{R}$ & $\mathrm{R}$ & $\mathrm{R}$ & $\mathrm{R}$ & $\mathrm{R}$ & ND \\
\hline \multicolumn{11}{|l|}{ Second-generation cephalosporin } \\
\hline Cefaclor & в & $\mathrm{R}$ & $\mathrm{R}$ & $\mathrm{R}$ & $\mathrm{R}$ & $\mathrm{R}$ & $\mathrm{R}$ & $\mathrm{R}$ & $\mathrm{R}$ & ND \\
\hline Cefotetan & $\mathrm{A}, \mathrm{B}$ & s & s & $\mathrm{s}$ & s & s & $\mathrm{R}$ & s & s & ND \\
\hline Cefuroxime & A & $\mathrm{R}$ & $\mathrm{R}$ & $\mathrm{R}$ & $\mathrm{R}$ & $\mathrm{R}$ & $\mathrm{R}$ & $\mathrm{R}$ & $\mathrm{R}$ & ND \\
\hline \multicolumn{11}{|l|}{ Third-generation cephalosporin } \\
\hline Cefoperazone & в & $\mathrm{R}$ & $\mathrm{R}$ & $\mathrm{R}$ & $\mathrm{R}$ & $\mathrm{R}$ & $\mathrm{R}$ & $\mathrm{R}$ & $\mathrm{R}$ & ND \\
\hline Cefotaxime & $\mathrm{A}, \mathrm{B}$ & $\mathrm{R}$ & $\mathrm{R}$ & $\mathrm{R}^{\mathrm{C}}$ & $R^{c}$ & $\mathrm{R}^{\mathrm{C}}$ & $\mathrm{R}$ & $\mathrm{R}^{\mathrm{C}}$ & $\mathrm{R}^{\mathrm{C}}$ & ND \\
\hline Cefpodoxime & в & $\mathrm{R}$ & $\mathrm{R}$ & $\mathrm{R}$ & $\mathrm{R}$ & $\mathrm{R}$ & $\mathrm{R}$ & $\mathrm{R}$ & $\mathrm{R}$ & ND \\
\hline Ceftazidime & A & $\mathrm{R}^{\mathrm{C}}$ & $\mathrm{R}^{\mathrm{C}}$ & ND & $\mathrm{R}^{\mathrm{C}}$ & $\mathrm{R}^{\mathrm{C}}$ & $\mathrm{R}^{\mathrm{C}}$ & $\mathrm{R}^{\mathrm{C}}$ & $\mathrm{R}^{\mathrm{C}}$ & $\mathrm{R}$ \\
\hline Ceftibuten & в & $\mathrm{R}$ & $\mathrm{R}$ & $\mathrm{R}$ & $\mathrm{R}$ & $\mathrm{R}$ & $\mathrm{R}$ & $\mathrm{s}$ & $\mathrm{R}$ & ND \\
\hline Ceftriaxone & A & $\mathrm{R}^{\mathrm{C}}$ & $\mathrm{R}^{\mathrm{C}}$ & $\mathrm{R}^{\mathrm{C}}$ & $R^{c}$ & $R^{C}$ & $\mathrm{R}$ & $\mathrm{R}^{\mathrm{C}}$ & $\mathrm{R}^{\mathrm{C}}$ & ND \\
\hline \multicolumn{11}{|c|}{ Third-generation cephalosporin/inhibitor } \\
\hline Ceftazidime/avibactam & B & $\mathrm{s}$ & $\mathrm{s}$ & $\mathrm{s}$ & $\mathrm{s}$ & s & $\mathrm{s}$ & $\mathrm{s}$ & s & s \\
\hline \multicolumn{11}{|l|}{ Fourth-generation cephalosporins } \\
\hline Cefepime & $A, B$ & $\mathrm{R}$ & $\mathrm{R}$ & $\mathrm{R}$ & $\mathrm{R}$ & $\mathrm{R}$ & $\mathrm{R}$ & $\mathrm{R}$ & $\mathrm{R}$ & $\mathrm{R}$ \\
\hline \multicolumn{11}{|l|}{ Fifth-generation cephalosporins } \\
\hline Ceftaroline & в & $\mathrm{R}$ & $\mathrm{R}$ & $\mathrm{R}$ & $\mathrm{R}$ & $\mathrm{R}$ & $\mathrm{R}$ & $\mathrm{R}$ & $\mathrm{R}$ & ND \\
\hline Fifth-generation cephalosporins/ & & & & & & & & & & \\
\hline Ceftolozane/tazobactam & B & s & s & s & s & s & s & s & s & s \\
\hline Phenicol & & & & & & & & & & \\
\hline Chloramphenicol & в & $\mathrm{R}$ & s & $\mathrm{R}$ & $\mathrm{R}$ & I & I & I & $\mathrm{R}$ & ND \\
\hline Phosphonates & & & & & & & & & & \\
\hline Phoosphomycin & B & ND & ND & ND & ND & ND & s & ND & ND & $\mathrm{R}$ \\
\hline Glycylcicline & & & & & & & & & & \\
\hline Tigecyclin & A & $s$ & $\mathrm{~s}$ & s & s & $s$ & s & s & s & ND \\
\hline Nitrofurans & & & & & & & & & & \\
\hline Nitrofurantoin & в & ND & ND & ND & ND & ND & $\mathrm{R}$ & ND & ND & ND \\
\hline Polymyxins & & & & & & & & & & \\
\hline Colistina & A & $s$ & s & s & s & $\mathrm{s}$ & $\mathrm{s}$ & $s$ & s & s \\
\hline Quinolones & & & & & & & & & & \\
\hline Second-generation quinolones & & & & & & & & & & \\
\hline Ciprofloxacin & $\mathrm{A}, \mathrm{B}$ & $\mathrm{R}$ & $\mathrm{R}$ & $\mathrm{R}$ & $\mathrm{R}$ & $\mathrm{R}$ & $\mathrm{R}$ & $\mathrm{R}$ & $\mathrm{R}$ & $\mathrm{R}$ \\
\hline Third-generation quinolones & & & & & & & & & & \\
\hline Levofloxacin & A & $\mathrm{s}$ & $\mathrm{s}$ & $\mathrm{R}$ & s & $\mathrm{s}$ & $\mathrm{R}$ & $\mathrm{R}$ & $\mathrm{R}$ & $\mathrm{R}$ \\
\hline Sulfonamides & & & & & & & & & & \\
\hline Trimethoprim/sulfamethoxazol & $\mathrm{A}, \mathrm{B}$ & $\mathrm{R}$ & $\mathrm{R}$ & $\mathrm{R}$ & $\mathrm{R}$ & $\mathrm{R}$ & $\mathrm{R}$ & $\mathrm{R}$ & $\mathrm{R}$ & ND \\
\hline Tetracyclines & & & & & & & & & & \\
\hline Tetracycline & A & $\mathrm{R}$ & s & $\mathrm{R}$ & $\mathrm{R}$ & $\mathrm{R}$ & $\mathrm{R}$ & $\mathrm{R}$ & $\mathrm{R}$ & ND \\
\hline
\end{tabular}

Abbreviations: R, resistant; $\mathrm{S}$, sensitive; I, intermediate; ND, Not determined.

Microdilution method (MicroScan autoScan-Neg Combo 67, Beckman Coulter B1017-421)

b Disk diffusion, modifier Kirby-Bauer method (BIO-RAD, 71080280; 71080180; 12008071; 71080280; 71080280; 71080180. OXOID, CT0264B; CT1880B; CT0193B; CT1612B; CT1662B; CT1941B; CT0183B. BBL, 231659; 231691; 231592; 231652; 231655; 231695)

${ }_{R}$, positive to extended-spectrum beta-lactamases (ESBL) production 


\begin{tabular}{|c|c|c|c|c|c|c|}
\hline \multirow{2}{*}{ Strain code } & \multirow{2}{*}{ MicroScan } & \multicolumn{5}{|c|}{ Molecular Identification } \\
\hline & & BLAST \% Similarity & Reference Strain & $\begin{array}{l}\text { EzBioCloud \% } \\
\text { Similarity }\end{array}$ & Reference Strain & Fragment Length \\
\hline Hemo72 & Klebsiella pneumoniae & K. pneumoniae 100 & DSM 30104 & $\begin{array}{l}\text { K. pneumoniae subsp } \\
\text { pneumoniae } 99.1\end{array}$ & DSM 30104 & 1500 bp \\
\hline H1064 & K. pneumoniae & K. pneumoniae 100 & DSM 30104 & $\begin{array}{l}\text { K. pneumoniae subsp } \\
\text { pneumoniae } 100\end{array}$ & DSM 30104 & 1456 bp \\
\hline H1206 & K. pneumoniae & K. pneumoniae 100 & DSM 30104 & $\begin{array}{l}\text { K. pneumoniae subsp } \\
\text { pneumoniae } 99.1\end{array}$ & DSM 30104 & 1520 bp \\
\hline Sec2 & K. pneumoniae & K. pneumoniae 100 & DSM 30104 & $\begin{array}{l}\text { K. pneumoniae subsp } \\
\text { pneumoniae } 100\end{array}$ & DSM 30104 & 1425 bp \\
\hline Uro6 & Escherichia coli & E. fergusonii 100 & ATCC 35469 & E. fergusonii 99.92 & ATCC 35469 & 1420 bp \\
\hline $\operatorname{Sec} 23$ & E. coli & E. fergusonii 100 & ATCC 35469 & E. fergusonii 99.93 & ATCC 35469 & 1464 bp \\
\hline Sec15 & E. coli & E. fergusonii 100 & ATCC 35469 & E. fergusonii 99.93 & ATCC 35469 & 1462 bp \\
\hline Uro42 & $\begin{array}{c}\text { Pseudomonas } \\
\text { aeruginosa }\end{array}$ & P. aeruginosa 100 & DSM 50071 & P. aeruginosa 100 & JCM 5962 & 1452 bp \\
\hline
\end{tabular}

Funding/Support: The authors state that there was no specific funding for this work.

Informed Consent: The participants' parents gave their free and informed consent to use the biological material analyzed in this study.

\section{References}

1. WHO. WHO's first global report on antibiotic resistance reveals serious, worldwide threat to public health.2014, [cited 25 November 2020]. Available from: https://www.who.int/mediacentre/news/releases/2014/ amr-report/en/.

2. WHO. Draft political declaration of the high-level meeting of the General Assembly on antimicrobial resistanceitle. 2016, [cited 25 November 2020]. Available from: https://www.un.org/pga/71/wpcontent/uploads/sites/40/2016/09/DGACM_GAEAD_ESCABAMR-Draft-Political-Declaration-1616108E.pdf.

3. Yusef D, Shalakhti T, Awad S, Algharaibeh H, Khasawneh W. Clinical characteristics and epidemiology of sepsis in the neonatal intensive care unit in the era of multi-drug resistant organisms: A retrospective review. Pediatr Neonatol. 2018;59(1):35-41. doi: 10.1016/j.pedneo.2017.06.001. [PubMed: 28642139].

4. Bandyopadhyay T, Kumar A, Saili A, Randhawa VS. Distribution, antimicrobial resistance and predictors of mortality in neonatal sepsis. J Neonatal Perinatal Med. 2018;11(2):145-53. doi: 10.3233/NPM-1765. [PubMed: 29991144].

5. Mutlu M, Aslan Y, Akturk Acar F, Kader S, Bayramoglu G, Yilmaz G. Changing trend of microbiologic profile and antibiotic susceptibility of the microorganisms isolated in the neonatal nosocomial sepsis: a 14 years analysis.J Matern Fetal Neonatal Med.2020;33(21):3658-65. doi: 10.1080/14767058.2019.1582633. [PubMed: 30760078].

6. Axford SB, Andersen CC, Stark MJ. Patterns of placental antimicrobial resistance in preterm birth before 30 completed weeks gestation complicated by preterm prelabour rupture of membranes. Aust N Z
J Obstet Gynaecol. 2020;60(4):509-13. doi: 10.1111/ajo.13087. [PubMed: 31650540].

7. Mahmoudi S, Mahzari M, Banar M, Pourakbari B, Haghi Ashtiani MT, Mohammadi M, et al. Antimicrobial resistance patterns of Gramnegative bacteria isolated from bloodstream infections in an Iranian referral paediatric hospital: A 5.5-year study.J Glob Antimicrob Resist. 2017;11:17-22. doi: 10.1016/j.jgar.2017.04.013. [PubMed: 28729206].

8. Tang B, Chen Y, Zhang L, Chang J, Xia X, Yang H. Complete genome sequence of colistin-resistant Escherichia fergusonii strain EFCF056. Microbiol Resour Announc. 2020;9(6). doi: 10.1128/MRA.01571-19. [PubMed: 32029565]. [PubMed Central: PMC7005130].

9. Gonzalez-Alba JM, Baquero F, Canton R, Galan JC. Stratified reconstruction of ancestral Escherichia coli diversification. BMC Genomics. 2019;20(1):936. doi: 10.1186/s12864-019-6346-1. [PubMed: 31805853]. [PubMed Central: PMC6896753].

10. Gaastra W, Kusters JG, van Duijkeren E, Lipman LJ. Escherichia fergusonii.Vet Microbiol.2014;172(1-2):7-12. doi:10.1016/j.vetmic.2014.04.016. [PubMed: 24861842].

11. Lindsey RL, Garcia-Toledo L, Fasulo D, Gladney LM, Strockbine N. Multiplex polymerase chain reaction for identification of Escherichia coli, Escherichia albertii and Escherichia fergusonii. J Microbiol Methods. 2017;140:1-4. doi: 10.1016/j.mimet.2017.06.005. [PubMed: 28599915]. [PubMed Central: PMC5603207].

12. Beghain J, Bridier-Nahmias A, Le Nagard H, Denamur E, Clermont O. ClermonTyping: an easy-to-use and accurate in silico method for Escherichia genus strain phylotyping. Microb Genom. 2018;4(7). doi: 10.1099/mgen.0.000192. [PubMed: 29916797]. [PubMed Central: PMC6113867].

13. Adesina T, Nwinyi O, De N, Akinnola O, Omonigbehin E. First detection of carbapenem-resistant Escherichia fergusonii strains harbouring beta-lactamase genes from clinical samples. Pathogens. 2019;8(4). doi: 10.3390/pathogens8040164. [PubMed: 31557915]. [PubMed Central: PMC6963453].

14. Savini V, Catavitello C, Talia M, Manna A, Pompetti F, Favaro M, et al. Multidrug-resistant Escherichia fergusonii: a case of acute cystitis. J Clin Microbiol. 2008;46(4):1551-2. doi: 10.1128/JCM.01210-07. [PubMed: 18256229]. [PubMed Central: PMC2292955]. 
15. Lagace-Wiens PR, Baudry PJ, Pang P, Hammond G. First description of an extended-spectrum-beta-lactamase-producing multidrugresistant Escherichia fergusonii strain in a patient with cystitis. $J$ Clin Microbiol. 2010;48(6):2301-2. doi: 10.1128/JCM.00364-10. [PubMed: 20410344]. [PubMed Central: PMC2884519].

16. Clinical and Laboratory Standards Institute (CLSI). Performance standards for antimicrobial susceptibility testing, M100 C supplement. 30th ed. USA: Clinical and Laboratory Standards Institute; 2020. 332 p.

17. Magiorakos AP, Srinivasan A, Carey RB, Carmeli Y, Falagas ME, Giske CG, et al. Multidrug-resistant, extensively drug-resistant and pandrug-resistant bacteria: an international expert proposal for interim standard definitions for acquired resistance. Clin Microbiol Infect. 2012;18(3):268-81. doi: 10.1111/j.1469-0691.2011.03570.x. [PubMed: 21793988].

18. Shane AL, Sanchez PJ, Stoll BJ. Neonatal sepsis. Lancet. 2017;390(10104):1770-80. doi: 10.1016/S0140-6736(17)31002-4. [PubMed: 28434651].

19. Funke G, Hany A, Altwegg M. Isolation of Escherichia fergusonii from four different sites in a patient with pancreatic carcinoma and cholangiosepsis. J Clin Microbiol. 1993;31(8):2201-3. doi: 10.1128/jcm.31.8.2201-2203.1993. [PubMed: 8370751]. [PubMed Central: PMC265723].

20. Gokhale VV, Therese KL, Bagyalakshmi R, Biswas J. Detection of Escherichia fergusonii by PCR-based DNA sequencing in a case of delayed-onset chronic endophthalmitis after cataract surgery. $J$ Cataract Refract Surg. 2014;40(2):327-30. doi: 10.1016/j.jcrs.2013.12.006. [PubMed: 24461505].

21. Lai CC, Cheng A, Huang YT, Chung KP, Lee MR, Liao CH, et al. Escherichia fergusonii bacteremia in a diabetic patient with pancreatic cancer. J Clin Microbiol. 2011;49(11):4001-2. doi: 10.1128/JCM.0535511. [PubMed: 21918030]. [PubMed Central: PMC3209106].

22. Baek SD, Chun C, Hong KS. Hemolytic uremic syndrome caused by Escherichia fergusonii infection. Kidney Res Clin Pract. 2019;38(2):2535. doi: 10.23876/j.krcp.19.012. [PubMed: 30970393]. [PubMed Central: PMC6577213].

23. Buehrle DJ, Shields RK, Clarke LG, Potoski BA, Clancy CJ, Nguyen MH. Carbapenem-resistant Pseudomonas aeruginosa bacteremia: Risk factors for mortality and microbiologic treatment failure. Antimi- crob Agents Chemother. 2017;61(1). doi: 10.1128/AAC.01243-16. [PubMed: 27821456]. [PubMed Central: PMC5192105].

24. Wi YM, Choi JY, Lee JY, Kang CI, Chung DR, Peck KR, et al. Antimicrobial effects of beta-Lactams on imipenem-resistant ceftazidimesusceptible Pseudomonas aeruginosa. Antimicrob Agents Chemother. 2017;61(6). doi: 10.1128/AAC.00054-17. [PubMed: 28373200]. [PubMed Central: PMC5444147].

25. Castanheira M, Deshpande LM, Costello A, Davies TA, Jones RN. Epidemiology and carbapenem resistance mechanisms of carbapenemnon-susceptible Pseudomonas aeruginosa collected during 2009-11 in 14 European and Mediterranean countries. J Antimicrob Chemother. 2014;69(7):1804-14. doi: 10.1093/jac/dku048. [PubMed: 24603963].

26. Mohsen L, Ramy N, Saied D, Akmal D, Salama N, Abdel Haleim MM, et al. Emerging antimicrobial resistance in early and late-onset neonatal sepsis. Antimicrob Resist Infect Control. 2017;6:63. doi: 10.1186/s13756017-0225-9. [PubMed: 28630687]. [PubMed Central: PMC5470277].

27. Berezin EN, Solorzano F, Latin America Working Group on Bacterial R. Gram-negative infections in pediatric and neonatal intensive care units of Latin America. J Infect Dev Ctries. 2014;8(8):942-53. doi: 10.3855/jidc.4590. [PubMed: 25116658].

28. Cifuentes Castaneda DD, Ramirez Duran N, Espinoza Rivera I, Marcela Caro Gonzalez L, Pablo Antonio Moreno Perez M, Mendieta Zeron H. Atypical Klebsiella species in a third level hospital as cause of neonatal infection. Jundishapur J Microbiol. 2018;11(3). doi:10.5812/jjm.62393.

29. Investigators of the Delhi Neonatal Infection Study collaboration. Characterisation and antimicrobial resistance of sepsis pathogens in neonates born in tertiary care centres in Delhi, India: a cohort study. Lancet Glob Health. 2016;4(10):e752-60. doi: 10.1016/S2214109X(16)30148-6. [PubMed: 27633433].

30. FDA. FDA Drug Safety Communication: FDA warns of increased risk of death with IV antibacterial Tygacil (tigecycline) and approves new Boxed Warning. Safety Announcement. 2013. Available from: https://www.fda.gov/drugs/drug-safety-and-availability/fdadrug-safety-communication-fda-warns-increased-risk-death-ivantibacterial-tygacil-tigecycline.

31. European Medicines Agency. Tigecycline, summary of product characteristics. 2006. Available from: https://www.ema.europa.eu/en/ medicines/human/EPAR/tygacil. 